\title{
Proses pemanfaatan modul bonggol jagung berbentuk balok menjadi material utama desain lampu
}

\author{
Muhamad Ediyansyah,,$^{1^{*}}$ Andry Masri ${ }^{2}$ \\ ${ }^{1,2}$ Program Studi Desain Produk, Institut Teknologi Nasional, Bandung, Indonesia
}

\begin{abstract}
The result of the exploration of corncob is a module in the form of a block at this stage of the corncob research with this form will be used as the main component of the product, this research was conducted with a material exploration approach, to explore the potential material of corncob which is expected to be a product that has novelty value. so an experiment is needed on corncobs. The experiments carried out were (1) the development of the physical treatment of the previous square module which had been explored by the industry to find the potential contained in the corncob. (2) Experiment with the corncob square module by using assembly methods and techniques in order to obtain new shapes and potentials. The research was conducted to obtain a product design with an emphasis on material aspects in order to obtain the characteristics of the corncob material. This research provides new opportunities and hopes for the community to have new creations in utilizing the corncob module.
\end{abstract}

Key words: exploration, corn cob, characteristics, and lamp design

\begin{abstract}
Abstrak
Hasil dari eksplorasi bonggol jagung adalah modul yang berbentuk balok pada tahap penelitian bonggol jagung ini dengan bentuk tersebut akan dimanfaatkan sebagai komponen utama produk, penelitian ini dilakukan dengan pendekatan eksplorasi material, untuk menggali potensi material bonggol jagung yang diharapakan menjadi sebuah produk yang memiliki nilai kebaruan, sehingga dibutuhkan eksperimen terhadap bonggol jagung. Eksperimen yang dilakukan adalah (1) pengembangan perlakuan fisik terhadap modul persegi sebelumnya yang telah dieksplorasi oleh industri untuk mencari potensi yang terdapat pada bonggol jagung tersebut. (2) Eksperimen modul persegi bonggol jagung dengan menggunakan metode dan teknik perakitan agar mendapatkan bentuk-bentuk dan potensi yang baru. Penelitian dilakukan untuk mendapatkan desain produk dengan penekanan pada aspek material agar mendapatkan karakteristik dari material bonggol jagung tersebut. Penelitian ini memberikan peluang baru dan harapan agar masyarakat memuiliki kreasi baru dalam memanfaatkan modul bonggol jagung.
\end{abstract}

Kata kunci: eksplorasi, bonggol jagung, karakteristik, dan desain lampu

\section{Pendahuluan}

Desain merupakan sebuah rangkaian yang didalamnya terdapat metodologi dalam proses merancang sebuah desain, design thinking merupakan sebutan proses desain. Proses desain merupakan perancangan desain yang tahapannya menentukan latar belakang untuk mendapatkan suatu masalah yang kemudian menjadi bahan analisis untuk memperoleh solusi desain yang tepat, sehingga ada proses pendekatan-pendekatan desain yang dicapai dan dilakukan.

Salah satunya adalah pendekatan design by doing Pendekatan ini pada awalnya dimulai pada tahun 1919 di Pendidikan desain pertama di dunia, yaitu sekolah Bauhaus yang didirikan oleh Walter Groupius. Prinsip utama yang digunakan oleh pendekatan ini merupakan upaya untuk mendapatkan bentuk-bentuk yang memiliki kebaruan (Masri, 2010).

\footnotetext{
* Corresponding author e-mail : ediyansyahmuhamad@gmail.com
} 
Ada juga pendekatan desain yang dilakukan dengan cara eksplorasi material untuk mendapatkan kebaruan. Dalam dunia desain, ekplorasi material dipahami sebagai upaya penggalian potensi yang dimiliki oleh material untuk mendapatkan gagasan baru (Andry \& Sachari, 2015).

Ungkapan tersebut menjelaskan bahwa proses desain merupakan suatu tahapan- tahapan untuk mencari nilai kebaruan, sama halnya dengan yang ungkapkan berikut: Keilmuan desain produk berkutat tentang bagaimana sebuah produk dapat membantu atau mendukung terwujudnya sebuah tujuan melalui terciptanya produk, dapat berupa mengatasi keterbatasan manusia, merubah perilaku, merubah kondisi, bahkan merubah pola pikir, dan semua hal tersebut terjadi karena adanya interaksi antara pengguna dengan produk dan lingkungan (Guspara, 2017). Proses desain secara umum menjelaskan bahwa kebaruan muncul disebabkan karena tujuan-tujuan tertentu untuk memenuhi kebutuhan manusia dengan berbagai pendekatan.

Bonggol jagung merupakan bagian tanaman dimana tempat melekatnya biji jagung yang berfungsi untuk melindungi biji jagung tersebut, bonggol jagung merupakan limbah tanaman yang telah diambil bijinya, bonggol jagung tersebut kemudian dibuang begitu saja, sehingga hanya akan meningkatkan jumlah sampah, hanya beberapa masyarakat yang memanfaatkan bonggol jagung menjadi olahan-olahan yang berguna, itupun hasilnya tidak optimal dan sebagian besar limbah bonggol jagung dibakar hanya menimbulkan pencemaran udara saja, dalam hali ini sebenarnya bonggol jagung memiliki potensi yang bermanfaat jika pengolahannya dilakukan dengan tepat untuk mengurangi limbah bonggol jagung dan mampu meningkatkan tingkat ekonomi. Peluang besar untuk memanfaatkan bonggol jagung sebagai bahan baku produk cukup menarik untuk dikembangkan dalam hal mengurangi limbah dengan pengembangan produk baru yang dapat memberikan nilai ekonomi yang tinggi (Wahmuda \& Puspitasari, 2015).

\section{Bahan dan metode}

Dengan itu pemanfaatan bonggol jagung masih memiliki banyak peluang untuk menjadi sebuah objek yang memiliki nilai ekonomi yang cukup tinggi dan mampu mengurangi limbah bonggol jagung tersebut. Penelitian ini dilakukan dengan cara eksplorasi material, untuk menggali potensi yang terdapat dalam bonggol jagung tersebut sehingga memiliki nilai kebaruan, karakteristik bonggol jagung, dan menjadi objek yang memiliki kualitas yang sangat tinggi. Pendekatan melalui eksplorasi material dilakukan dengan metode "design by doing”, artinya pemahaman terhadap karakteristik dilakukan dengan cara eksperimen-eksperimen berupa pemberian perlakuan terhadap sebuah material sebagai langkah untuk mengenal bagaimana material secara khas merespon perlakuan tersebut.

Oleh karena itu dibutuhkan perlakuan khusus yang dilakukan untuk mendapatkan olahan bonggol jagung yang memiliki nilai kebaruan, agar mendapatkan daya tarik masyarakat untuk memanfaatkan limbah bonggol jagung tersebut, sehingga mampu mengangkat perekonomian dari hal baru yang sebelumnya bonggol jagung dianggap tidak memiliki nilai ekonomi dan hanya dianggap limbah, hal tersebut harus ditempuh dengan cara pendekatan eksplorasi material (Masri \& Pasaribu, 2018)

Dalam memanfaatkan limbah bonggol jagung yang telah dilakukan yaitu dengan cara eksplorasi material, dari eksplorasi material tersebut menghasilkan banyak alternatif berupa modul. Modul yang dihasilkan jika diolah dan dikembangkan dengan baik mampu menghadirkan potensi-potensi yang dapat dimanfaatkan sebagai material sebuah produk.

Dari pengolahan dan pengembangan bonggol jagung, menghasilkan salah satu modul yang berbentuk balok yang dirasa memiliki potensi didalamnya oleh karena itu fokus yang dilakukan tertuju pada modul bonggol jagung tersebut, jika dikembangkan kembali berpotensi menjadi material untuk pembuatan produk. Untuk menggali potensi material modul bonggol jagung yang berbentuk balok diharapkan menjadi sebuah produk yang memiliki nilai kebaruan sehingga dibutuhkan eksperimen fisik terhadap bonggol jagung. Eksperimen yang dilakukan adalah pengembangan perlakuan fisik modul balok sebelumnya yang telah dieksplorasi untuk mencari potensi yang terdapat dari bonggol jagung tersebut. Eksperimen selanjutnya modul bonggol jagung yang berbentuk balok tersebut dirakit dengan teknik atau metode-metode untuk mendapatkan bentuk dan potensi yang baru. Oleh karena itu pendekatan “design by doing” tepat dilakukan seperti ungkapan yang dipaparkan oleh Dedy Ismail salah satu dosen desain produk ITENAS menyebutkan bahwa “design by doing” adalah pendekatan desain yang akan diterapkan dalam proses pencarian potensi material dan perancangan produk (Ismail, 2011).

Tahapan pertama yang dilakukan adalah dengan cara brainstorming untuk menemukan teknik untuk mencari metode perakitan modul bonggol jagung 
Muhamad Ediyansyah, Andry Masri

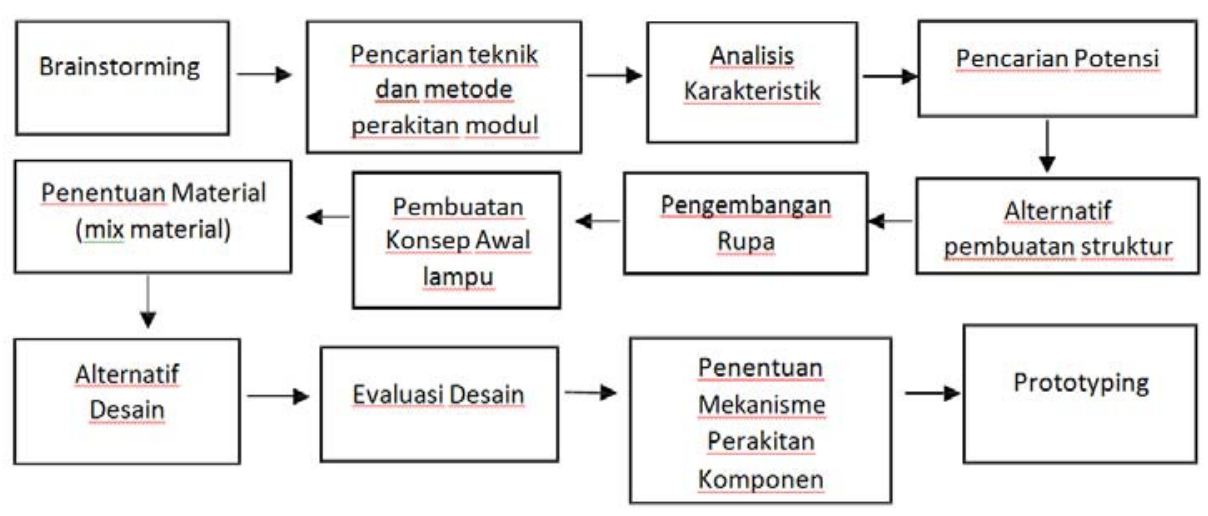

Gambar 1. Proses desain yang dilaksanakan

berbentuk persegi, kemudian menganalisis hasilnya untuk mencari potensi yang terdapat pada bonggol jagung sebagai komponen lampu (Gambar 1).

Tahapan pertama yang dilakukan adalah dengan cara brainstorming untuk menemukan teknik untuk mencari metode perakitan modul bonggol jagung berbentuk persegi, kemudian menganalisis hasilnya untuk mencari potensi yang terdapat pada bonggol jagung sebagai komponen lampu.

Eksperimen juga dilakukan untuk mencari alternatif struktur yang sesuai dengan teknik metode perakitan bonggol jagung. Setelah metode perakitan modul bonggol jagung berbentuk balok didapatkan, kemudian dilakukan proses pengembangan rupa dari alternatif struktur yang mana akan menentukan konsep awal lampu yang sesuai dengan rupa yang dihasilkan sebelumnya.

Proses selanjutnya adalah menentukan mix material yang mendukung dengan karakteristik bonggol jagung menggunakan metode 3D modeling dengan membuat beberapa alternatif desain, dari beberapa alternatif tersebut dilakukan evaluasi mengenai keterkaitan antara mix material dengan metode perakitan bonggol jagung yang telah ditentukan.

Setelah alternatif desain didapatkan kemudian menentukan mekanisme perakitan komponenkomponen bonggol jagung berserta lampu berupa sistem plug in - plug out agar memudahkan pada saat proses perawatan produk.

Proses terakhir merupakan pembuatan prototype untuk merealisasikan desain terpilih ke dalam bentuk rupa tiga dimensi dengan material bonggol jagung berserta mix material yang telah diputuskan.

\section{Hasil dan pembahasan}

Dari proses tersebut dihasilkan proses bahan baku bonggol jagung yang berbentuk balok dan silinder yang siap diolah menjadi berbagai macam produk disesuaikan dengan karakteristik bonggol jagung, namun untuk saat ini bahan baku bonggol jagung yang dominan digunakan adalah bahan baku yang berbentuk balok.

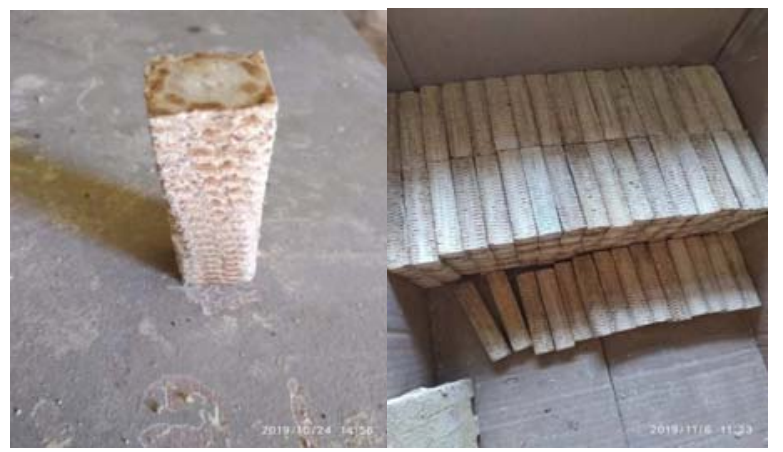

Gambar 1. Bahan baku modul berbentuk balok

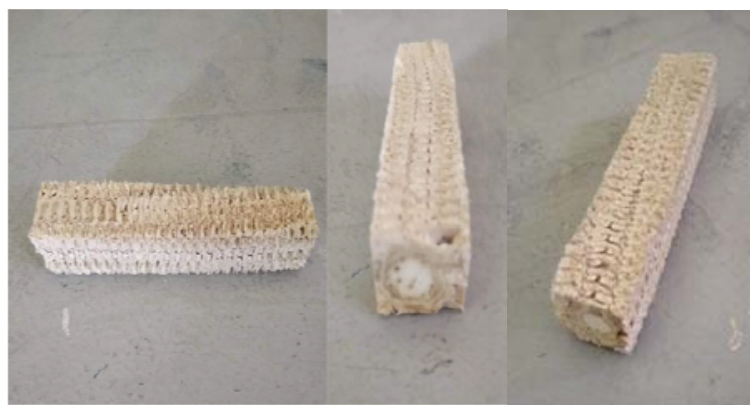

Gambar 2. Modul bonggol jagung berbentuk balok 


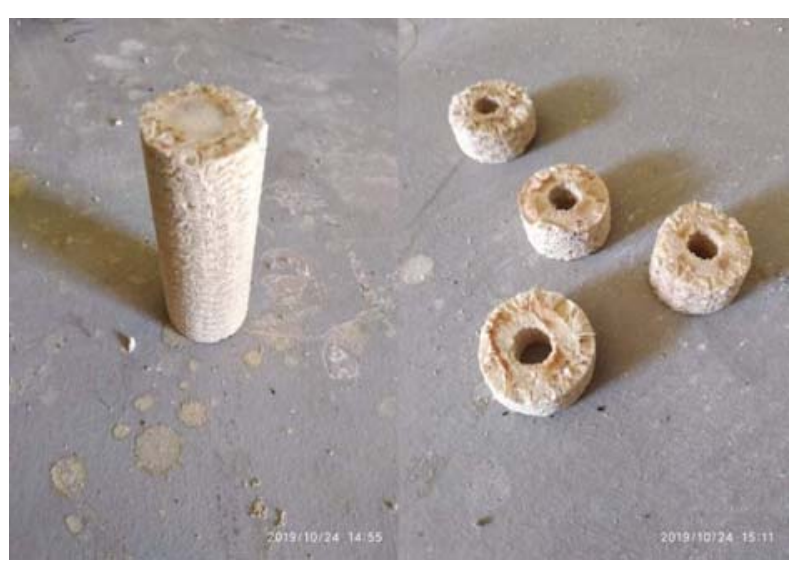

Gambar 3. Modul bonggol jagung berbentuk silinder

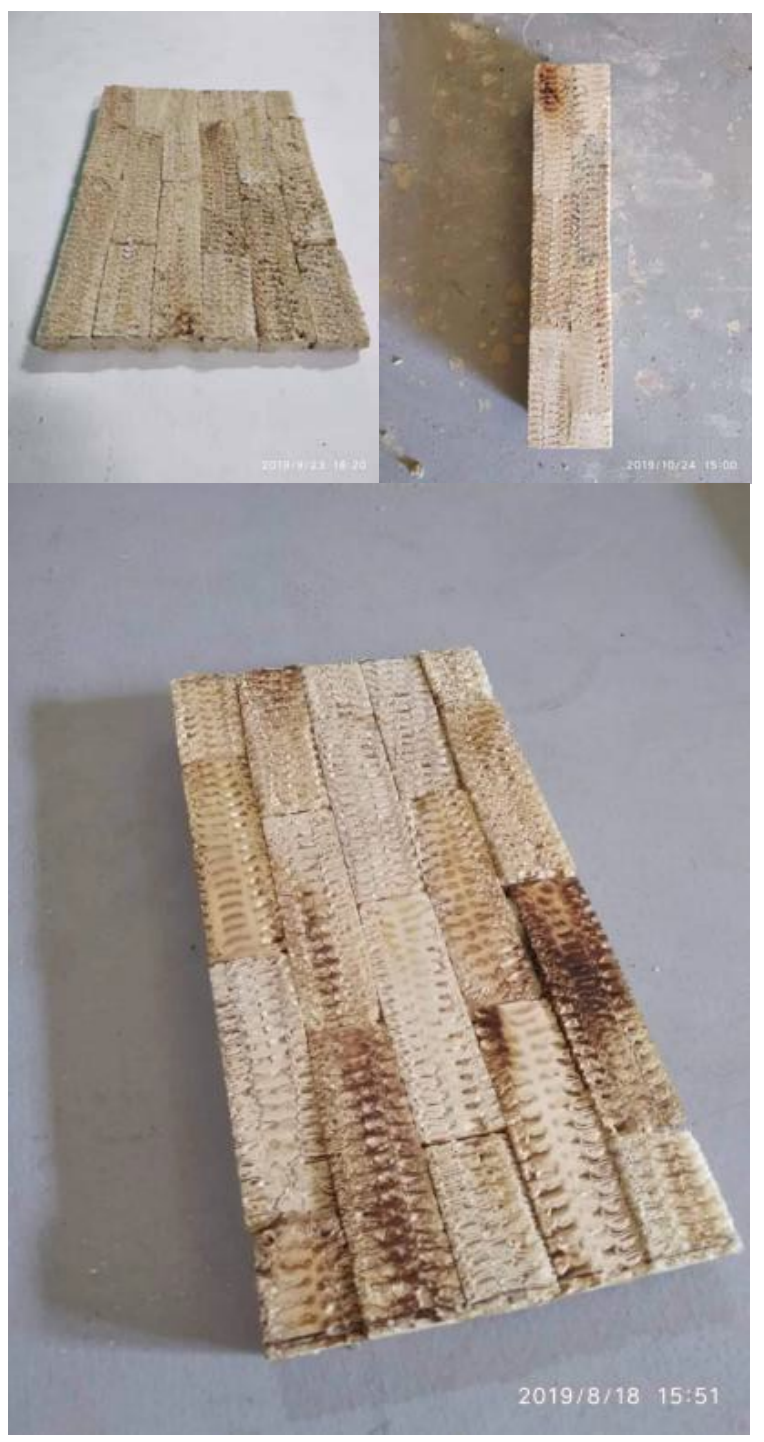

Gambar 4. Eksperimen modul bonggol jagung

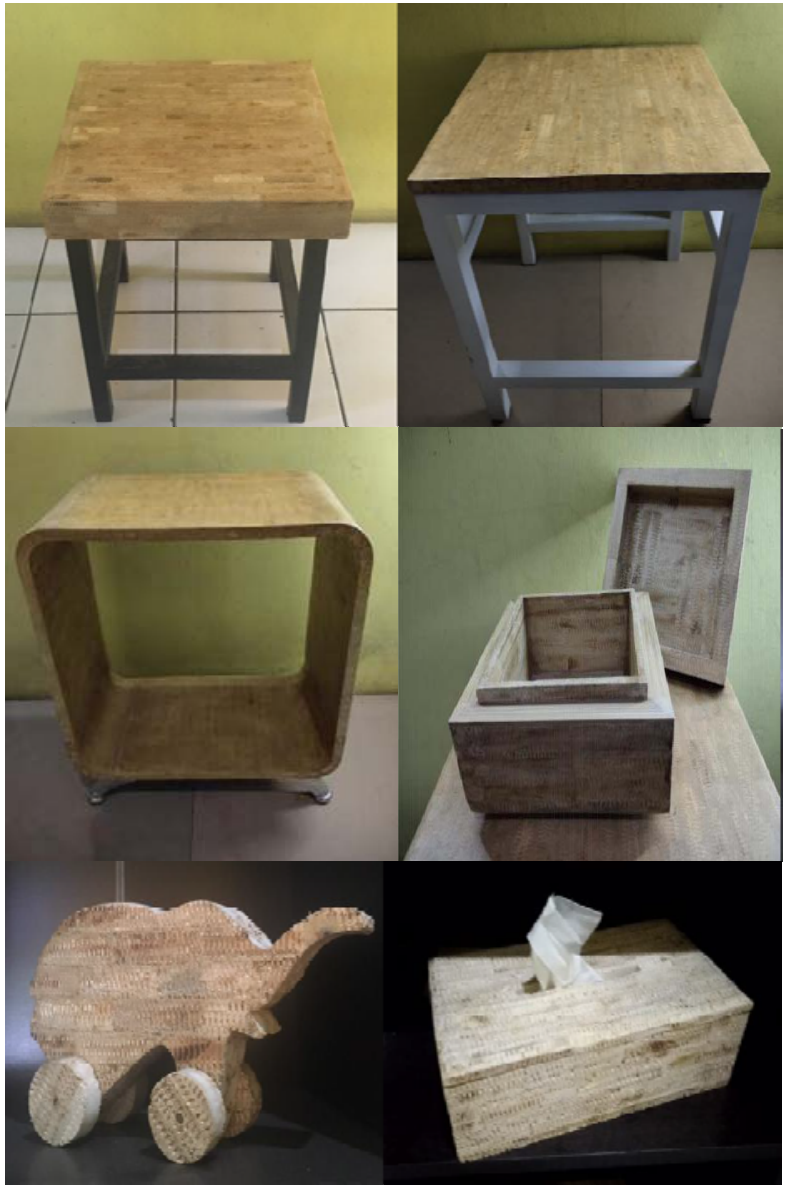

Gambar 5. Produk dari Modul Balok dari CV. Craftindo Kreasi

Modul bonggol jagung berbentuk balok diputuskan sebagai modul yang dipilih menjadi bentuk dasar modul sebagai material utama pada lampu. Bonggol jagung berbentuk balok tersebut memiliki panjang $10 \mathrm{~cm}$, lebar $2 \mathrm{~cm}$, dan tinggi $2 \mathrm{~cm}$.

Dari hasil analisis modul bonggol jagung berbentuk balok terdapat potensi yang cocok diterapkan menjadi produk lampu, karena pencahayaan lampu mampu mengekspose karakteristik visual bonggol jagung, dengan demikian dibutuhkan eksperimen teknik dan metode perakitan bentuk modul balok untuk mencari potensi agar mendukung karakteristik bonggol jagung. Analisis hasil eksperimen ditekankan pada karakteristik visual dan ketapan teknik perakitan dalam penyusunan tiap modul balok bonggol jagung. Alternatif desain dilakukan menyesuaikan dengan hasil pengembangan rupa modul bonggol jagung yang berbentuk balok untuk diterapkan sebagai komponen lampu (Gambar 6 \& 7). 
Muhamad Ediyansyah, Andry Masri

Proses pemanfaatan modul bonggol jagung berbentuk balok menjadi material utama desain lampu
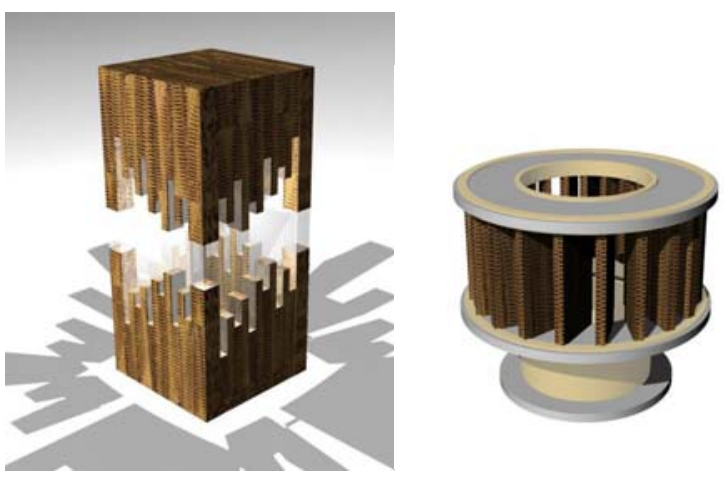

Gambar 6. Alternatif desain bonggol jagung (1) \& (2)
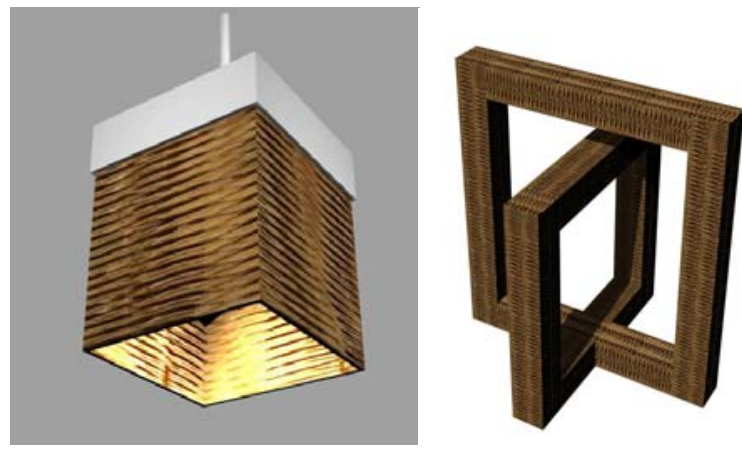

Gambar 7. Alternatif desain bonggol jagung (3) \& (4)
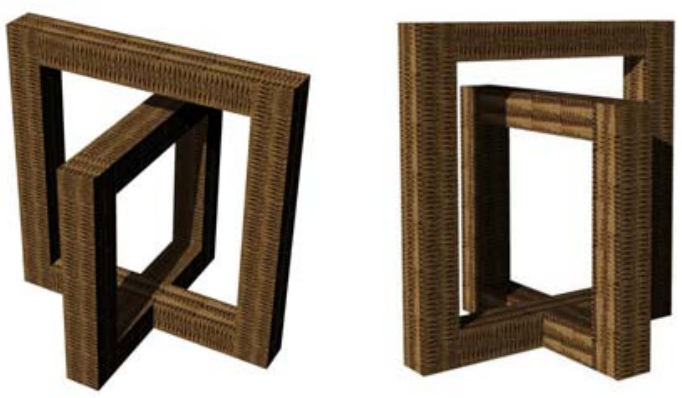

Gambar 8. Alternatif desain terpilih

Dari desain yang terpilih adalah desain yang memiliki bentuk geometris, dan simpel, pertimbangan bentuk simpel dan geometris menyesuaikan dengan karakteristik bonggol jagung yang berdasarkan dari hasil eksplorasi, bentuk geometris digunakan karena pemilihan modul bonggol jagung yang berbentuk persegi dan kemudian bentuk simpel juga memperkuat bentuk visual dari modul bonggol jagung tersebut.
Setelah alternatif terpilih (Gambar 8), selanjutnya penulis melakukan analisis pada komponen bonggol jagung untuk teknis pemasangan lampu. Teknik yang dilakukan adalah membuat profil alur permukaan komponen bonggol jagung menyesuaikan dengan dimensi lampu yang digunakan, lampu tersebut yaitu tipe lampu LED Neon Flex berwarna putih (Gambar 9). Pemasangan lampu disesuaikan dengan profil yang sudah dibuat sehingga posisi lampu mengikuti alur profil pada komponen bonggol jagung. Konfigurasi Jointing digunakan agar komponen bonggol jagung dapat memiliki fitur lepas-pasang dengan menggunakan sistem plug in - plug out (Gambar 10). Dowl digunakan sebagai sistem plug in - plug out, dowl yang digunakan adalah jenis dowl bambu berdiameter $0,5 \mathrm{~cm}$ dan pada setiap jointing menggunakan 2 buah dowl dengan kedalaman bor 3 $\mathrm{cm}$ perkomponen bonggol jagung, sehingga keperluan panjang dowl yaitu $6 \mathrm{~cm}$.

Mix material yang digunakan pada produk lampu bonggol jagung ini adalah berfungsi sebagai base dengan menggunakan material logam, sistem yang digunakan untuk pemasangan antara komponen bonggol jagung dan base logam adalah menggunakan sistem plug in - plug out juga.

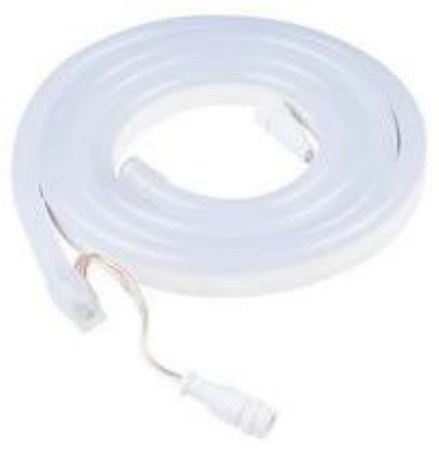

Gambar 9. LED Neon Flex
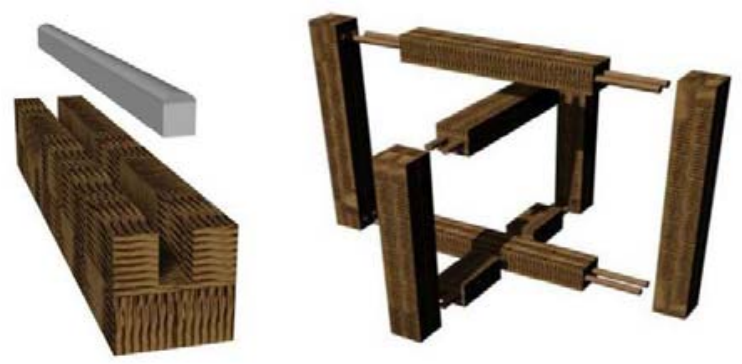

Gambar 10. Konfigurasi Sistem 

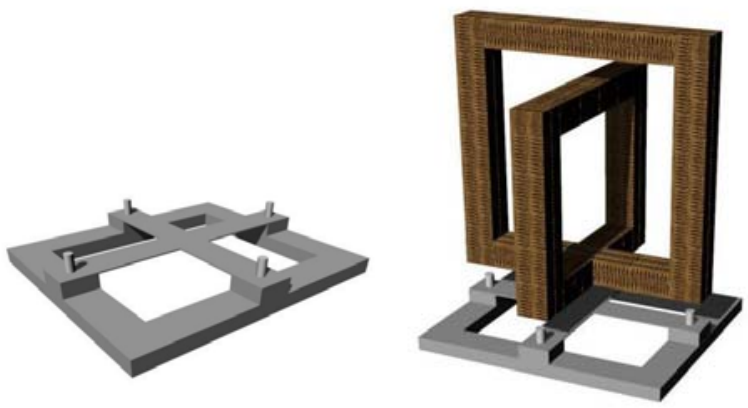

Gambar 11. Teknis pemasangan base dan bonggol jagung

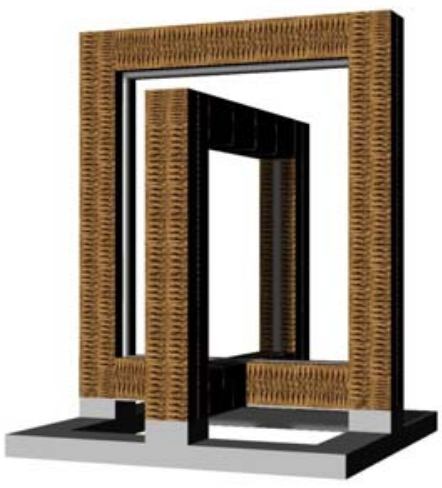

Gambar 15. Prototype

\section{Kesimpulan}

Ada beberapa tahapan proses dan keputusan dalam melakukan finishing modul yang berbentuk papan tersebut dengan cara mendempul terlebih dahulu permukaannya agar rata, karena bonggol jagung tersebut memiliki permukaan yang masih berlubang, karena bekas biji jagung yang menempel, dempul dicampurkan dengan serbuk bonggol jagung sisa potongan agar warna dempul yang dihasilkan sama dengan warnanya agar tidak menghilangkan karakteristik dari bonggol jagung tersebut.

Pemilihan lampu yang digunakan adalah lampu LED Neon Flex 12 volt berwarna putih. LED Neon Flex memiliki dimensi yang cukup kecil berbentuk persegi panjang dengan sifatnya yang linear memudahkan pada saat dipasangkan bersamaan dengan komponen bonggol jagung dan pemilihan lampu yang berwarna putih dikarenakan katagori warna putih merupakan warna yang netral, sehingga seimbang dengan warna bonggol jagung.

Konfigurasi sistem plug in - plug out dipakai karena sistem tersebut memiliki fitur yang bisa dilepas dan pasang yang berfungsi untuk memudahkan maintenance.

Pemilihan base dengan menggunakan material logam yang diwarnai putih juga bertujuan untuk menyeimbangi dengan warna bonggol jagung.

\section{Daftar pustaka}

Andry, Sachari, A. (2015). Konsep permainan dalam eksplorasi material untuk pengembangan craft. Disampaikan pada Seminar Nasional Strategi Indonesia Kreatif Universitas Widyatama Bandung 19 Maret 2015. Retrieved from http://lib.itenas.ac.id/kti/wp-content/uploads/2017/12/08KONSEP-PERMAINAN-DALAM-EKSPLORASIMATERIAL-UNTUK-pengembangan-craft.pdf

Guspara, W. A. (2017). Pendekatan material sebagai alternatif untuk pengembangan produk (Using material approach as an alternative for product development). INVENSI (Jurnal Penciptaan dan Pengkajian Seni), 2(2), 33-42

Ismail, D. (2011). Uji Fisik Bonggol Jagung Olahan sebagai Alternatif Bahan Baku dalam Konsep Produk Fungsional. Jurnal Rekayasa Institut Teknologi Nasional, Vol XII (2). 1-13

Masri, A. (2010). Pendekatan Desain Bagi Industri Kerajinan Kreatif Sebuah Usulan Bagi Program Implementasi Ekonomi Kreatif Di Sektor Industri Kerajinan Indonesia. Disampaikan pada Seminar Nasional "Strategi UMKM \& IKM Menghadapi "Asean China Free Trade Area" (ACFTA) dan Inplementasinya dalam upaya memperkuat dan mengembangkan kemampuan diri, Universitas Pakuan Bogor, 10 April 2010. Retrieved from http://lib.itenas.ac.id/kti/wpcontent/uploads/2017/12/010-Pendekatan-Desain-BagiIndustri-Kerajinan-Kreatif-Sebuah-Usulan-unpak.pdf

Masri, A, Pasaribu, Y.M. (Eds). (2018). Buku Craft dan Desain di Indonesia, Sudut Pandang Akademik dan Pelaku. Bandung. Aliansi Desain Produk Industri Indonesia.

Wahmuda, F., \& Puspitasari, R. (2015). Pengembangan Desain Produk dari Tongkol Jagung Berbasis Industri Kreatif. In Prosiding Seminar Nasional Sains dan Teknologi Terapan SNTEKPAN III 2015, 627-262 